\title{
La debida diligencia del inversionista extranjero. Un concepto bidimensional ${ }^{\star}$
}

\author{
Foreign Investors' Due Diligence: Bidimensional Concept \\ A devida diligência do investidor estrangeiro. Um conceito \\ bidimensional
}

\author{
DANIEL RIVAS-RAMÍREZ $Z^{* \star}$
}

FECHA DE RECEPCIÓN: 21 DE ABRIL DE 2021. FeCHA DE APROBACIÓN: 5 DE OCTUBRe DE 2021

Doi: https://doi.org/10.12804/revistas.urosario.edu.co/sociojuridicos/a.10518

Para citar este artículo: Rivas-Ramírez, D. (2022). La debida diligencia del inversionista extranjero. Un concepto bidimensional. Estudios Socio-Jurídicos, 24(1), 39-69. https://doi.org/10.12804/revistas.urosario.edu.co/ sociojuridicos/a.10518

\section{RESUMEN}

Una de las características propias del derecho internacional de las inversiones es la forma en la que, a partir de su lenguaje, su estructura y su funcionamiento, está pensado para ofrecer mayores herramientas para los inversionistas extranjeros. De allí que en realidad las relaciones que de él se derivan sean asimétricas, beneficiando en buena medida a los particulares y dejando con pocas herramientas a los Estados; en particular en el marco de los arbitrajes internacionales de inversión. Ahora bien, un concepto que ha sido utilizado en algunas oportunidades y que ha servido como herramienta para la defensa de los Estados es el de la debida diligencia de los inversionistas. No obstante, se trata de una noción disímil y en buena medida indeterminada. Este artículo propone, a partir de un estudio teórico, doctrinario y 'jurisprudencial', definir el concepto de la debida diligencia - de los inversionistas- a través de dos dimensiones de las que se derivan obligaciones claras y exigibles para los inversionistas respecto de sí mismos, los Estados receptores y los individuos a los que afectan con sus inversiones.

Palabras clave: inversión extranjera; arbitraje de inversión; debida diligencia; Colombia.

* El autor agradece a la profesora Paola Andrea Acosta Alvarado por sus enriquecedores comentarios para el desarrollo del presente artículo.

** Egresado de la Facultad de Derecho de la Universidad Externado de Colombia; Diploma de Profundización en Protección Supranacional de los Derechos Humanos de la Università degli Studi di Perugia y del Instituto Eurolatinoamericano de Estudios para la Integración. Coordinador editorial de la revista Latin American Law Review de la Universidad de los Andes (Colombia) y del Centro de Investigación y Docencia Económicas (México). Correo electrónico: danielrivasram@hotmail.com ORCID: https://orcid.org/0000-0002-8191-9996 


\section{ABSTRACT}

One of the main traits of international investment law is its design to offer greater tools for foreign investors based on its language, structure, and operation. Hence, the relations derived from it are asymmetrical, benefiting investors to a large extent and leaving States with few tools, particularly in the framework of international investment arbitration. However, a concept that has been occasionally used and has served as a tool for the defense of States is the investor's due diligence. Nonetheless, it is a dissimilar and largely indeterminate notion. This article proposes to define the investor's due diligence as a bidimensional concept from which clear and enforceable obligations are derived for investors with respect to themselves, host States, and the individuals affected by their investments based on a theoretical, doctrinal, and jurisprudential study.

Keywords: Foreign investment; investment arbitration; due diligence; Colombia.

\section{RESUMO}

Uma das características próprias do direito internacional de investimentos é a forma como, com base em sua linguagem, estrutura e funcionamento, foi elaborado para oferecer maiores ferramentas aos investidores estrangeiros. Assim que, na realidade, as relações que dele decorrem são assimétricas, beneficiando em grande parte os indivíduos e deixando os Estados com poucas ferramentas; em particular, no âmbito das arbitragens internacionais de investimento. Contudo, um conceito que tem sido utilizado em algumas ocasiões e que tem servido como instrumento de defesa dos Estados é o da devida diligência dos investidores. No entanto, trata-se de uma noção diferente e em grande parte indeterminada. Este artigo propõe, com base em um estudo teórico, doutrinal e 'jurisprudencial', definir o conceito da devida diligência - de investidores- através de duas dimensões das quais derivam obrigações claras e exequíveis para os investidores com relação a si próprios, os Estados destinatários e os indivíduos afetados por seus investimentos.

Palavras-chave: investimento estrangeiro; arbitragem de investimentos; devida diligência; Colômbia. 


\section{Introducción}

La concepción tradicional del concepto de debida diligencia en el derecho internacional siempre ha estado asociada a las actuaciones de los Estados; sin embargo, creemos que en la filigrana de la inversión extranjera $-\mathrm{y}$ su afectación a los ordenamientos jurídicos, sociales y económicos nacionales - también puede ser exigida a los inversores extranjeros. Es por esta razón que en este texto nos ocuparemos de presentar las diferentes razones por las cuales podemos sostener que los inversionistas extranjeros, similar a los Estados, también tienen que cumplir con un nivel mínimo de diligencia y, de no hacerlo, podrá ser utilizado en su contra en un proceso de arbitraje de inversión tanto a nivel nacional como internacional.

Para tales efectos, las páginas que siguen se dividirán en cuatro partes. La primera presentará los elementos generales de la figura de la debida diligencia en el derecho internacional. La segunda desarrollará los fundamentos de los que nosotros hemos llamado las obligaciones intrínsecas del inversionista, correspondiente a aquellas que él tiene para consigo y su inversión. Posteriormente, en la tercera, expondremos las obligaciones externas que debe atender, en concreto respecto del Estado receptor de la inversión y de los individuos en general como titulares de derechos humanos. Finalmente, tras haber revisado las dos dimensiones del deber de debida diligencia de los inversionistas, cerraremos el artículo con el análisis de su (in)cumplimiento en el caso de Cosigo y Tobie Mining.

\section{La debida diligencia en el derecho internacional}

El debate en torno a la naturaleza jurídica de los inversionistas en el derecho internacional es una cuestión inagotable y, por lo tanto, requiere de un estudio detallado y extenso, el cual, debido al objeto de este trabajo, no abordaremos. Pese a ello, desde la práctica diaria de sus actividades podemos ver que, en ocasiones, tal y como lo hemos señalado en otras oportunidades, se comportan como verdaderos sujetos de derecho internacional público dentro del régimen especializado del 
derecho de las inversiones (Rivas-Ramírez, 2018). Esto quiere decir que no solo son amparados por los tratados bilaterales de inversión como objetos de protección, sino que, a la vez, en virtud de ellos, tienen una serie de obligaciones, como el deber de debida diligencia (Chetail, 2014).

Esta obligación ha sido entendida tradicionalmente como el deber de atención y cuidado que le es exigible a cualquier individuo en el desarrollo normal de sus actividades, sean públicas o privadas. Esto en particular debido a que se ha tratado como un principio general del derecho de las naciones civilizadas, cuyo origen tuvo lugar en el derecho civil y penal de estos Estados (Kulesza, 2016, p. 19). No obstante, con el paso de los años y el desarrollo de esta a través de la jurisprudencia y el derecho blando, se le ha reconocido una naturaleza flexible y versátil frente a su inescindible relación con la responsabilidad internacional de los Estados (p. 29).

Tal versatilidad puede apreciarse en la construcción paulatina del concepto a través de las decisiones de tribunales internacionales. Así, por ejemplo, en el caso de Alabama Claims Arbitration, el tribunal de arbitramento empleó la noción de debida diligencia respecto del mantenimiento de la neutralidad de un Estado ante una situación entre otros Estados (tribunal de arbitramento, reclamación de Estados Unidos de América contra Gran Bretaña relativa a Alabama, 1872). Posteriormente, en el caso Lotus, la Corte Permanente de Justicia Internacional introdujo de manera implícita la figura, al establecer en cabeza de los Estados el deber de tomar acciones razonables para proteger a los extranjeros en su territorio de actos criminales de terceros (CPII, SS Lotus, 1927).

Después, a partir del caso del Canal de Corfu, 1946, el concepto empezó a utilizarse con mayor normalidad y contundencia en las controversias internacionales (ILA, 2014, p. 4). De allí que ahora el principio de debida diligencia sea utilizado frecuentemente en diversos campos del derecho internacional, como la neutralidad, la protección diplomática, los derechos humanos y la protección del medio ambiente (Cheteil, 2014, p. 126).

Con relación a su desarrollo normativo, la cuestión ha sido aún más débil. Los tratados internacionales han omitido incluir de manera explícita este tipo de disposiciones. No obstante, los draft articles sobre la responsabilidad internacional de los Estados por los hechos ilícitos 
internacionalmente de la Comisión de Derecho Internacional, en su artículo $2^{\circ}$, relativo a la atribución del ilícito internacional -según la versión comentada-, funda la responsabilidad en la existencia de cierto grado de culpa, culpabilidad, negligencia o necesidad de debida diligencia (ILC, 2001a, art. $2^{\circ}$ ). Así mismo, los draft articles sobre la prevención del daño transfronterizo en actividades peligrosas, en su artículo $3^{\circ}$, incluyen de forma más clara la obligación de la debida diligencia en clave de la prevención y minimización del riesgo (ILC, 2001b).

Por otra parte, aun cuando el derecho internacional del medio ambiente ha supuesto un importante avance y desarrollo en términos de la delimitación de la debida diligencia internacional, el Grupo de Estudio sobre Debida Diligencia de la Asociación de Derecho Internacional ha concluido que se trata de un concepto amplio cuya materialización en cada régimen de derecho internacional varía de cierta manera. Sin embargo, en su segundo reporte publicado en julio de 2016, indicó que al menos era factible identificar algunos contenidos mínimos relacionados con la razonabilidad, el buen gobierno, un nivel internacional mínimo de trato, el control territorial y frente a actores no estatales, el nivel de riesgo y los las actividades potencialmente riesgosas y la mala fe (ILA, 2016, pp. 7-13).

Es debido a tal indeterminación conceptual que aún no se cuenta en la doctrina y la jurisprudencia internacional ${ }^{1}$ con una definición unívoca de la debida diligencia, y por lo que el único elemento catalizador de las definiciones y su aplicación es la de la prevención del riesgo (Stephens, 2009, p. 158). Esto en últimas quiere decir que la obligación de debida diligencia de los Estados podría entenderse como una obligación de medio y no de resultado. Por este motivo, para autores como Martti Koskenniemi, es preferible entender la debida diligencia como una técnica de proceduralización - derivada del derecho internacional consuetudinario- relacionada con un proceso de toma de decisiones informadas y fundadas, más allá que con el wrongdoing durante tal momento decisorio (Koskenniemi, 2006, p. 391).

En esta categoría, ubicamos de manera general las decisiones proferidas por los diferentes tribunales internacionales, incluidos los tribunales de arbitramento de inversiones y el órgano de solución de diferencias de la OMC. Lo hacemos para efectos de referirnos a una categoría general que los agrupe a todos, aun cuando somos conscientes de que en estos últimos dos casos es impreciso hablar de jurisprudencia. 
Es a partir de este tipo de razonamientos que, para algunos, la debida diligencia se trata de una norma primaria, más allá que un simple estándar conductual de los Estados. No obstante, como tal no quiere decir que sea aplicable de manera indistinta y unívoca a todos los Estados. En realidad, corresponde a una obligación relativa que está condicionada a la propia capacidad estatal (ILA, 2014).

En el caso del derecho internacional de las inversiones, el deber de debida diligencia ha cobrado una incipiente relevancia a través de algunos de los estándares de protección que se prevén en los acuerdos internacionales de esta índole, a saber, la cláusula de protección y seguridad, el nivel mínimo de trato y el trato justo y equitativo. Ahora bien, aun cuando la primera de ellas corresponde a la garantía de seguridad física y jurídica de la inversión; la segunda sobre ofrecer un trato conforme con los estándares mínimos internacionales; y la tercera, como su nombre lo indica, a dar un tratamiento justo y equitativo a los inversionistas, las tres implican un trato objetivo por parte del Estado al inversionista (ILA, 2014, pp. 7-8).

En cuanto a su utilización en el seno de los tribunales internacionales de arbitraje de inversión, vemos que se trata de una práctica aún más remota. No obstante, encontramos algunos pocos casos en donde se ha empleado. Es así como de Ronald S. Lauder versus Czech Republic se desprende que la cláusula de protección y seguridad no implica una obligación objetiva de protección absoluta, sino que se entiende cumplida cuando el Estado receptor haya desplegado una debida diligencia por medio de las medidas tendientes a mitigar el riesgo y evitar el daño del inversionista. Por lo tanto, no podría concluirse que podría haber responsabilidad del Estado cuando se tratase de actuaciones de terceros no atribuibles al Estado. ${ }^{2}$ En ese mismo sentido, decisiones más recientes, como las de los tribunales de arbitraje en los casos de Suez, Sociedad General de Aguas de Barcelona S.A. y Vivendi Universal S.A. y AWG

2 "There is no further definition of this obligation in the Treaty. The Arbitral Tribunal is of the opinion that the Treaty obliges the Parties to exercise such due diligence in the protection of foreign investment as reasonable under the circumstances. However, the Treaty does not oblige the Parties to protect foreign investment against any possible loss of value caused by persons whose acts could not be attributed to the State. Ronald S. Lauder v. The Czech Republic" (Uncitral, Final award, 2001, para. 308). 
Group td. contra Argentina, han sido absolutamente claras al establecer que esta cláusula supone un deber de debida diligencia y que bajo ninguna circunstancia puede ser entendida como un supuesto de responsabilidad objetiva. ${ }^{3}$ Incluso, en el caso Naturgy Energy Group S.A. y Naturgy Electricidad Colombia S.L. versus Colombia, el tribunal mantuvo este razonamiento al señalar que "la PSP no es un estándar de responsabilidad absoluta por el que se compromete automáticamente la responsabilidad de un Estado basándose en pruebas de que la inversión del inversionista sufrió una pérdida física" (ICSID, Naturgy Energy Group S.A. y Naturgy Electricidad Colombia S.L. vs. Colombia, 2021, párr. 562).

Ahora bien, tal y como lo mencionábamos antes, la obligación de debida diligencia y, en este caso, las medidas de protección y seguridad para los inversionistas -y sus inversiones - son modulables respecto de cada Estado. Esto en el entendido de que, aun cuando la protección tiene fundamento en el derecho internacional, este no puede desconocer las limitaciones intrínsecas de cada uno de los Estados. Es así como en el caso de Técnicas Medioambientales Tecmed S.A. contra México, el tribunal sostuvo que el cumplimiento del estándar de protección debía ser determinado con base en que este se hubiese realizado con debida diligencia a través de las medidas que resultasen razonables de acuerdo con los parámetros de un Estado democrático. ${ }^{4}$

Con relación a los estándares del nivel mínimo de trato y el trato justo y equitativo, la debida diligencia ha sido entendida en los mismos términos de la cláusula de protección y seguridad. Esto debido a que, como suele ocurrir con la mayoría de los estándares de protección, estos se sobreponen entre ellos, en especial cuando el trato justo y equitativo

3 "The fact that the 'full protection and security' standard implies only an obligation of due diligence, as opposed to strict liability, has also been widely recognized in more recent arbitral case decisions" Suez, Sociedad General de Aguas de Barcelona S.A. and Vivendi Universal S.A. versus The Argentine Republic, ARB/03/19, Decision on liability, 30 July 2010; AWG Group Ltd. versus The Argentine Republic, ARB/03/19, Decision on liability, 30 July 2012, para. 164.

4 "The Arbitral Tribunal agrees with the Respondent, and with the case law quoted by it, in that the guarantee of full protection and security is not absolute and does not impose strict liability upon the State that grants it. At any rate, the Arbitral Tribunal holds that there is not sufficient evidence supporting the allegation that the Mexican authorities, whether municipal, state, or federal, have not reacted reasonably, in accordance with the parameters inherent in a democratic state, to the direct action movements conducted by those who were against the Landfill" Técnicas Medioambientales Tecmed S.A. versus The United Mexican States, ICSID Case ARB (AF)/00/2, Award, 29 May 2003, para. 177. 
está de por medio (ICSID, Jan de Nul N.V. \& Dreding International N.V. c. Arab Republic of Egypt, 2008b).

\section{La primera dimensión de la debida diligencia del inversionista: las obligaciones intrínsecas}

Desde nuestra perspectiva y como se verá a continuación, al hablar de la debida diligencia de los inversionistas extranjeros - dentro de sus actividades de inversión amparadas por los tratados bilaterales de inversión (TBI) - es necesario distinguir dos dimensiones o dos tipos de obligaciones diferentes. Las primeras, que nosotros hemos llamado intrínsecas y que son las que desarrollaremos en este acápite, corresponden a aquellas que los inversionistas tienen consigo mismos. En otras palabras, podríamos hablar de las obligaciones morales que tienen para el correcto ejercicio de su actividad económica. Las segundas, las cuales serán atendidas en el acápite siguiente, son las obligaciones que, en razón de su actividad, deben cumplir a favor de otras personas -naturales o jurídicas-.

Para efectos de poder explicar el sentido y alcance de las obligaciones intrínsecas del inversionista extranjero, es preciso detenernos primero en la definición de la inversión y las etapas que se cumplen para efectos de materializar tal inversión.

En términos generales, dentro del derecho internacional de las inversiones no hay un concepto unívoco de lo que es una inversión. Pese a ello, de la lectura sistemática de los acuerdos de inversión, es posible identificar unos elementos comunes y transversales en lo que respecta a este concepto: las nociones de activos, compromiso de capital, riesgo y expectativa de ganancia. En el caso de los acuerdos de inversión ratificados por Colombia, los encontramos presentes en más de quince de ellos. ${ }^{5}$

A partir de ellos, podríamos concluir que una inversión consiste en un acto de disposición de unos activos, que se comprometen para

\footnotetext{
5 Ver, por ejemplo, los tratados de libre comercio con Estados Unidos y Canadá, y los acuerdos de inversión con Japón, Corea, Perú y el Reino Unido, entre otros.
} 
un fin determinado, asumiendo una serie de riesgos a cambio de una expectativa legítima de ganancia o plusvalía. En pocas palabras, consiste en la apuesta que hace el inversionista en un momento y lugar determinados con miras a multiplicar su capital (Schreuer, 2000).

En esa misma dirección, los tribunales internacionales de arbitraje de inversión han ido procurando una definición uniforme, al menos en cuanto a las características esenciales de la inversión. Es así como desde el caso de Salini et al. contra Marruecos, los elementos definitorios de la inversión han sido cuatro: el aporte de activos (o dinero), un período durante el cual se realizará la operación, el elemento del riesgo y una contribución a la economía nacional del Estado receptor (ICSID, Salini Costruttori S.p.A. and Italstrade S.p.A. vs. Kingdom of Morocco, 2000).

Aun cuando podríamos ahondar en la distinción entre el tipo de inversiones directas e indirectas, en realidad lo que nos interesa es la noción o elemento de riesgo en el seno de la inversión. El riesgo hace referencia directa a una contingencia o, si se quiere, a la probabilidad de un daño; en este caso, en contra de la inversión. Esto quiere decir que, desde el principio, el inversionista es consciente de que hay un abanico de factores que pueden incidir en su proyecto y los cuales representan un riesgo para sus ganancias. En últimas, se trata de una limitación a las expectativas de réditos.

Ahora bien, el exponerse voluntariamente a un riesgo suele significar que la esperanza de beneficios es mayor y, por lo tanto, vale la pena asumirlo. No obstante, en las ciencias económicas y en los mercados de capitales, el riesgo es un factor que ha de ser considerado con detenimiento y, en la medida de lo posible, mitigado a su mínima expresión. Es así como en el manejo de las inversiones la lógica propia de esta actividad económica sugiere tomar las medidas conducentes a la reducción del riesgo a la hora de efectuar la inversión.

Con el objetivo de mostrar cómo los inversionistas extranjeros diligentes deben evaluar con detenimiento el riesgo y administrar correctamente el proceso de toma de decisiones relativas a la inversión, presentaremos primero la actividad del inversionista en clave del obrar de un hombre de negocios y, posteriormente, los parámetros y guías internacionales que se han ofrecido a los inversionistas para que acojan voluntariamente. 


\section{El inversionista extranjero, responsable, diligente y protector de su inversión}

Tal y como lo acotábamos al principio, la debida diligencia como concepto, norma y obligación tiene origen en el derecho nacional de los Estados y, por lo tanto, sus primeros vestigios -al menos en las sociedades de derecho continental- se remontan a las figuras y principios del derecho romano. Por ello, haremos referencia a dos de ellas, las cuales, vale aclarar, son inescindibles: la diligentia quam in suis y la figura del buen pater familias.

En primer lugar, la diligentia quam in suis es ampliamente reconocida como uno de los principios fundamentales del derecho romano, que, además, se ha traslapado al derecho internacional público en general (Hernández, 2013, p. 42). Este consiste en que cualquier individuo -o Estado- debe actuar con la diligencia con la que actuaría si se tratase de sus cuestiones propias. Tradicionalmente este criterio ha sido empleado respecto de los Estados, al igual que como ocurre con el estándar de debida diligencia (Fellmeth \& Horowitz, 2011).

No obstante, creemos que es replicable para el caso de los inversionistas extranjeros en el entendido de que las más de las veces las inversiones extranjeras son realizadas por personas jurídicas trasnacionales que se componen por numerosos equipos de empleados. En tal sentido, se puede plantear la necesidad de aplicar el principio elípticamente de tal manera que las filiales -y sus trabajadores locales-, los equipos de estudio de mercado y quienes participan en el sistema de evaluación de riesgo tendrían que obrar como si se tratase de sus propios bienes. Esto implicaría que, para empezar, cada una de las células de la multinacional estaría llamada a actuar con pericia y diligencia a la hora de sugerir, tomar decisiones o actuar en representación del organismo trasnacional.

Por otra parte, la institución del buen pater familias también resulta relevante en el entendido de que es la que le da origen a la noción 'moderna' del buen hombre de negocios. Esta, aun cuando se trata de una noción propia del derecho privado nacional y frecuentemente utilizada por nuestra legislación nacional para determinar el grado de culpa, es una de las manifestaciones prístinas de la debida diligencia 
(Neme Villarreal, 2006). Así, por ejemplo, en términos comerciales, hace referencia al despliegue de una conducta diligente por parte del comerciante en sus negocios (Sabogal, 2012, p. 127).

En el derecho internacional, la noción del bonus pater familias ha sido rebatida y en muchas oportunidades descartada debido a que a los Estados no se les exige una diligencia media, sino, por el contrario, la de más alto nivel (Pissilo-Mazzeschi, 1992). Sin embargo, bajo ese argumento, el estándar del hombre de negocios podría ser perfectamente aplicable al inversionista no solo por la coincidencia sustancial en el objeto de regulación en el derecho nacional, sino también porque, al no ser un sujeto de derecho internacional público con el mismo poder y capacidad del Estado, parecería apenas lógico aplicar un estándar un tanto menor que al del primero.

La variable que estaría por determinar con relación a la aplicación de este segundo criterio a los inversionistas corresponde al nivel mínimo de diligencia que debería regir sus decisiones. Para tales efectos es necesario apelar a la teoría general de la inversión. ¿Cuáles son los pasos para realizar una inversión? ¿Qué factores han de ser tenidos en cuenta? Son tan solo un par de ejemplos de las preguntas que servirán para delimitar lo mínimo exigible a un inversionista extranjero con base en su propia lex artis.

Para ello, lo primero es entender que la inversión extranjera es el resultado de un proceso de decisiones, para las cuales el inversionista debe estar informado sobre los costos, los riesgos y los beneficios de su inversión. En consecuencia, es necesario tener claro cuáles son las diferentes etapas de ese proceso decisorio, por lo que a continuación enunciaremos brevemente cuáles son y en qué consisten.

En términos generales, cualquier proceso de inversión, sea nacional o trasnacional, debe transcurrir a través de cuatro momentos o etapas: la planeación financiera, la identificación y priorización del proyecto, la programación y ejecución de la inversión, y, finalmente, el monitoreo y evaluación de esta (Kaganova, 2011, p. 30). Otros autores y organizaciones excluyen la última etapa del proceso en el entendido de que la utilidad de esa revisión crítica de la inversión se vería frente a otra inversión futura (Mcdearman \& Donahue, 2016). Bajo esta óptica, solo nos ocuparemos de analizar la debida diligencia en el proceso 
de planeación e implementación, y, por lo tanto, prescindiremos del estudio de la última etapa.

Así las cosas, antes de iniciar con el proceso de inversión, es preciso que el inversionista realice todo lo relacionado con la planeación financiera. Para ello, es necesario que la empresa ubique y disponga de sus recursos, haciendo las proyecciones correspondientes con el tipo de proyecto de inversión que perseguirá y el lugar en el que lo ejecutará. De esta manera y conforme con la teoría del paradigma ecléctico, es imperioso determinar las ventajas con las que se cuenta en términos diferenciales en el mercado (Denisia, 2010, pp. 104-110). En este contexto, el inversionista debe tomar en especial consideración una de tres razones que servirían para justificar su interés de inversión en un nicho determinado. Estas son la transferencia fácil y barata de propiedad exclusiva, la posibilidad de establecer un monopolio en el mercado o tener una ventaja diferencial en términos tecnológicos.

Posteriormente, en la etapa de identificación y priorización del proyecto, es esencial que se evalúe el lugar en donde se quiere hacer la inversión, y, en consecuencia, se lleven a cabo los estudios frente a la viabilidad del proyecto en ese contexto determinado. Es así como respecto a la locación de la inversión el inversionista debe hacer una trazabilidad de los beneficios valorables pecuniariamente a partir de los factores cuantitativos y cualitativos que pueden incidir en ella. Esto en particular teniendo en cuenta que, desde la práctica, los mismos inversionistas han identificado dos bloques de factores relevantes: aquellos relacionados con sus intereses comerciales y económicos; y otros relacionados con los factores institucionales y regulatorios (IMF $\mathcal{E}$ World Bank, 2003, p. 15). En otras palabras, el inversionista debe hacer una evaluación concienzuda que trascienda el mercado en cuestiones económicas y para lo cual debe abordar factores de infraestructura, sociales, políticos y jurídicos, particularmente en lo referente al sistema de licencias y al marco normativo (McGowan Jr. E Moeller, 2009).

Con base en la información y los factores evaluados en estas dos primeras etapas, el inversionista debe tomar una decisión informada y debidamente fundamentada. Así, en la etapa de la implementación, el inversionista debe asegurarse de que la inversión atienda a los parámetros que se identificaron y establecieron en las primeras dos etapas. De este 
modo, además, debe cerciorarse de que los factores exógenos a la inversión, como los procesos políticos, sociales o culturales del lugar donde se hace la inversión, no la afecten más allá de los riesgos calculados. En tal sentido, el inversionista no puede confiarse de manera absoluta en el rol de garante que cumple el Estado receptor, sino que él mismo también debe prestar atención y realizar lo que esté a su alcance para proteger su inversión (Kaganova, 2011).

Así las cosas, el inversionista extranjero debe, en aras de operar bajo el estándar mínimo de diligencia propio de las reglas de su actividad económica, planear financieramente su inversión, valorar los factores que pueden representar un riesgo en su desarrollo y ejecutarla con base en los hallazgos y parámetros autodefinidos en la etapa previa. Esto cobra especial relevancia cuando se trata de economías emergentes y Estados en vía de desarrollo, debido a que en ellos hay una mayor volatilidad en los factores riesgosos para la inversión (Henisz \& Zelner, 2010).

Es así como sendos tribunales internacionales de arbitraje de inversión han usado el criterio de la debida diligencia del inversionista extranjero como una herramienta para zanjar la decisión. De este modo, por ejemplo, en Parkerings-Copagnier as contra Lituania, los árbitros establecieron que las expectativas del inversionista solo serían legítimas y podrían ser protegidas siempre que hubiesen sido alcanzadas actuando con la debida diligencia que se espera del inversionista (ICSID, Parkerings-Compagniet AS vs. Republic of Lithuania, 2007). En ese mismo sentido, en Biwater Gauff contra Tanzania, el tribunal determinó que el estándar de trato justo y equitativo solo podría amparar al inversionista en los casos en los que sus expectativas fueren legítimas y razonables con base en los actos diligentes que hubiese realizado (ICSID, Biwater Gauff (Tanzania) Ltd. vs. United Republic of Tanzania, 2008a).

Otros tribunales han sido un tanto más conservadores en el alcance de la figura de la debida diligencia del inversionista al emplearla únicamente para efectos de reducir la condena de los Estados. Así, por ejemplo, en Iurii Bogdanov et al. contra Modavia, se disminuyó considerablemente la suma a la que fue condenada el Estado en el entendido de que el inversionista no había actuado con la diligencia suficiente y, por lo tanto, la responsabilidad de la violación del tratado podía tenerse 
como compartida (SCC, Iurii Bogdanov, Agurdino-Invest Ltd. and AgurdinoChimia JSC vs. Republic of Moldova).

Por último, vale la pena destacar las consideraciones del tribunal de arbitramento constituido en el caso Naturgy Energy Group S.A. y Naturgy Electricidad Colombia S.L. versus Colombia. En él, de manera consistente, los árbitros castigaron la falta de diligencia por parte de los inversionistas en la adquisición de la empresa Electricaribe. En concreto, valoraron de forma negativa la falta de pruebas que demostraran la debida diligencia antes de la inversión y la opinión de un testigo que sustentaba esta situación.

En conclusión, la diligentia quam in suis y el correcto sistema de prevención y mitigación de los riesgos derivados de la inversión que debe considerar y elaborar el inversionista extranjero serán dos elementos clave para su éxito. De lo contrario, la afectación de su capital por factores exógenos que fueron evaluados pero no prevenidos resultará en una infracción a su obligación moral, pero, lo que es más grave en términos económicos para el inversionista, en la afectación a sus intereses económicos.

\section{La diligencia voluntaria: el caso de las directrices de la OCDE}

Así mismo, existe otra serie de deberes relacionados con la debida diligencia de los inversionistas que no tienen origen en la actividad en sí misma, sino, por el contrario, en su voluntad de obligarse a ser más diligentes de lo normal. En concreto, nos referimos a la posibilidad que tienen las multinacionales de acoger, bajo su propia voluntad, las diferentes directrices que la OCDE ha proferido en los últimos años en miras de mejorar el desempeño de las multinacionales en los escenarios local e internacional.

En el año 1976 los Estados parte de la OCDE profirieron la Declaración sobre Inversión Internacional y Empresas Multinacionales, con la que además establecieron las directrices o principios guía para este tipo de corporaciones trasnacionales (Cantú Rivera, 2015). Estos últimos se construyeron como una serie de recomendaciones a las empresas para efectos de armonizar las políticas gubernamentales y los actos de ellas, 
con la finalidad de aumentar la confianza recíproca entre el Estado, las multinacionales y la sociedad (OECD, 2011, p. 13).

Es así como, con el objetivo de mantener y fomentar la inversión extranjera directa al mismo tiempo que el desarrollo sostenible del país, Colombia adoptó ese grupo de principios y estándares en diciembre de 2011 (Ostau de la Font de León E Niño Chavarro, 2015). De esa manera, tanto nuestro país como los demás Estados parte buscan que las multinacionales en sus actividades diarias en todos los Estados tengan en cuenta no solo las normas que los amparan bajo una sombrilla de protección, sino también la legislación nacional y los estándares internacionales (OECD, 2016).

Este grupo de directrices, además de proponer unas cuestiones generales en torno a los mismos principios y las políticas generales, prevé disposiciones específicas en nueve categorías diferentes: información, derechos humanos, trabajo y relaciones industriales, medio ambiente, corrupción y extorsión, intereses del consumidor, ciencia y tecnología, competencia y tributación, a las cuales se espera que las multinacionales se acojan voluntariamente. Debido al objeto de este artículo, señalaremos únicamente las directrices que consideramos relevantes para el concepto de debida diligencia. ${ }^{6}$

En cuanto al deber de debida diligencia, las directrices para multinacionales incluyen una tríada de disposiciones tendientes a la identificación, mitigación y prevención del riesgo en distintos sectores. Estos son los artículos 10, 11 y 12 del apartado II sobre políticas generales. Con ellos se establece que las multinacionales deberían atender una debida diligencia basada en el riesgo para prevenir, mitigar, pero, a la vez, responder por los diferentes impactos que genera la inversión en las diversas materias que abarca el documento (medio ambiente,

6 Creemos vital señalar que, aun cuando somos conscientes de que de las directrices se derivan eventuales obligaciones de las empresas respecto del Estado, la sociedad y para sí mismo, por razones metodológicas hemos decidido incluirlas dentro de la categoría de obligaciones intrínsecas del inversionista. Esto debido a que, a pesar de esa obligación triple, en realidad se trata de un deber o compromiso que asume o asumiría el inversionista para mejorar su situación general en el Estado receptor y sus dinámicas operacionales en estricto sentido. 
derechos humanos, competencia, entre otros). ${ }^{7}$ Igualmente, el artículo 12 establece lo siguiente: "Esforzarse por impedir o atenuar los impactos negativos, aun en los casos en que las empresas no hayan contribuido a los mismos, si están directamente relacionados con sus actividades, productos o servicios en virtud de una relación comercial. Esto no ha de interpretarse como una transferencia de la responsabilidad de la entidad que causa el impacto negativo hacia la empresa con la que mantiene una relación comercial".

Con ellos, vemos que en realidad lo que se pretende desde las directrices es establecer un deber de diligencia debida considerablemente alto para los inversionistas. Esto en particular en el entendido de que le imponen una carga sustancial al establecer la obligación - eventual-de mitigar los impactos de otras intervenciones o factores. ${ }^{8}$

Adicionalmente y aun cuando no se trate de una obligación propia de la debida diligencia, creemos que es fundamental destacar que, en caso tal en el que la(s) multinacional(es) asumieran los compromisos derivados de las directrices, estas representarían otra carga adicional en torno a cumplir con parámetros previstos nacional e internacionalmente para el bienestar y protección de bienes especialmente importantes.

Así mismo, conviene señalar que desde el año 2010 ya se habían previsto de manera específica en la Guía de la debida diligencia para cadenas de suministro de minerales de áreas conflictivas y de áreas de altos riesgos, y que después fueron acogidas por los Principios Ruggie en lo que respecta a los procesos de extracción, transporte, manejo, intercambio, procesamiento, refinamiento, manufactura y comercio de productos con minerales provenientes de ese tipo de zonas (OECD, 2016). Finalmente,

7 "Artículo 10. Implementar la debida diligencia basada en los riesgos incorporándola, por ejemplo, a sus sistemas de gestión de riesgos, con el fin de identificar, prevenir o atenuar los impactos negativos, reales o potenciales, que se describen en los apartados 11 y 12 e informar sobre cómo se reacciona ante dichos impactos negativos. La naturaleza y el alcance de la debida diligencia dependen de las circunstancias de cada situación particular".

"Artículo 11. Evitar que las actividades propias generen o contribuyan a generar impactos negativos en los campos contemplados por las directrices y tomar las medidas necesarias para tratarlos cuando se produzcan dichos impactos".

8 Es importante aclarar que por carga no nos referimos a una transferencia de la responsabilidad. De hecho, solo hacemos referencia a que se le está imponiendo una carga adicional al inversionista sin que ello signifique eximir de responsabilidad a quien generaría los efectos. 
con relación a las directrices y a la guía de la OCDE, conviene hacer hincapié en su naturaleza voluntaria para las multinacionales $\mathrm{y}$, por lo tanto, para el inversionista extranjero. Pese a ello, es de resaltar que, para autores como French y Stephens, estos documentos tienen la virtualidad de apoyar el proceso de aparición de un instrumento vinculante para esos sujetos (ILA, 2016).

\section{La otra dimensión: las obligaciones respecto de los individuos y el Estado}

En cuanto a la segunda dimensión de la debida diligencia de los inversionistas extranjeros, encontramos que en realidad se derivan dos tipos de deberes diferentes. Los primeros relacionados con las obligaciones que se asumen respecto de terceros en virtud de los Principios Ruggie y otros instrumentos de responsabilidad social empresarial. Los segundos, los deberes que se contraen necesariamente por la integración al mercado y el ordenamiento jurídico nacional.

\section{Los Principios Ruggie como obligaciones de RSE frente a terceros}

Para empezar, es importante distinguir que, a diferencia de lo que ocurre con lo mencionado en el acápite anterior, el deber de debida diligencia en el campo de la responsabilidad social empresarial y los derechos humanos tiene un alcance sustancialmente diferente. Mientras que en lo relacionado con los negocios y la inversión propiamente dicha la debida diligencia corresponde a un ejercicio de investigación tendiente a la mitigación del riesgo antes de la toma de decisiones, en el campo de los derechos humanos se entiende como un ejercicio de revisión periódica y remediación de las violaciones a derechos (ILA, 2016).

Dentro de las iniciativas globales por establecer un instrumento que resultase vinculante para las empresas multinacionales y sirviese para garantizar el respeto e integridad de los derechos humanos en los escenarios empresariales, se inició el proyecto de un código de conducta para las empresas en materia de responsabilidad social empresarial. Pese a lo anterior y en particular debido a la falta de consenso, el resultado de 
este ejercicio fue la decisión unánime del Consejo de Derechos Humanos de acoger en 2011 los Principios guía de empresa y derechos humanos, también conocidos como los Principios Ruggie (OACNUDH, 2011).

Estos principios, los cuales tienen naturaleza de soft law, se encuentran estructurados sobre un pilar triple del respeto de los derechos humanos que se deriva del principio 15. El primero de ellos es el deber que tienen los Estados de proteger los derechos humanos; el segundo, la responsabilidad de las empresas de respetar los derechos humanos; $y$, finalmente, el tercero, la necesidad de un remedio efectivo en aquellos casos en los que haya algún tipo de vulneración (Ruggie, s. f.), lo que quiere decir que el instrumento de los principios guía prevé obligaciones no solo para los inversionistas, sino también para los Estados.

Pese a ello, nosotros solo nos ocuparemos de nombrar y analizar los principios relacionados con las obligaciones eventuales de los inversionistas y que se pueden enmarcar dentro de la idea de la debida diligencia. Así las cosas, nos concentraremos en los principios 15 y del 17 al 21.

Tal y como lo señalábamos al hablar de los pilares, el principio 15 , en su literal b, contiene de manera expresa una guía con relación a la debida diligencia por parte de la multinacional. En concreto, la disposición la exige en materia de derechos humanos para identificar, prevenir y mitigar el impacto que tiene su actividad - en este caso la inversiónsobre los derechos humanos. Sin embargo, debido a su naturaleza pilar, su contenido real se desarrolla en los principios siguientes.

El principio 17 establece que el proceso de debida diligencia, es decir, la identificación, la prevención y la mitigación de las consecuencias negativas de las actividades, debe incluir una evaluación sustancial de los efectos tanto reales como potenciales que estas puedan tener en adelante sobre los derechos humanos. En ese mismo sentido, es necesario que, tras la evaluación, se integren las conclusiones al respecto, se actúe, se comunique sobre la estrategia y se dé seguimiento a la forma en la que se atenderán los efectos negativos.

Por otra parte, se determina que el deber de atender y remediar las consecuencias sobre los derechos humanos se extiende también a aquellas actividades que, aun cuando no sean realizadas por ellas mismas, tengan una relación directa con sus operaciones, sus productos o sus servicios. No obstante, la complejidad de la función de debida 
diligencia es relativa al tamaño, la naturaleza y el contexto operacional de la compañía. Finalmente, el principio concluye que el proceso de remediación debe ser continuo, dado que la naturaleza de los derechos humanos es dinámica.

El principio 18 conduce a que dentro del ejercicio de gestión de riesgos propio de la actividad - es decir, de la inversión en nuestro casose incluya la evaluación de los riesgos para los derechos humanos. Para tales efectos se exhorta a recurrir a expertos en el tema y la realización de consultas sustantivas a las comunidades o grupos que podrían verse afectados en el desarrollo de la actividad de la multinacional. Esto quiere decir que, en el caso latinoamericano, en aquellos supuestos en los que se viesen afectados o comprometidos los derechos e intereses de comunidades indígenas o afrodescendientes, los inversionistas estarían llamados a practicar una especie de consulta previa.

Con relación a la integración de las conclusiones para la mitigación y remedio de los derechos humanos afectados, el principio 19 requiere que tal responsabilidad se asigne a las personas indicadas y competentes dentro de la empresa. Así mismo, indica que las medidas exigidas varían según sea el grado de proximidad entre los efectos negativos a los derechos humanos y la actividad comercial que se desempeña.

Finalmente, el principio 20 instaura la obligación de verificar que se estén llevando a cabo las medidas de mitigación de los efectos sobre los derechos humanos a través de indicadores cualitativos y cuantitativos, como a la vez de personas externas.

Como se puede ver, con ellos se edifica un mecanismo - al menos incipiente- de defensa, promoción y garantía de los derechos humanos, puesto que el estándar de debida diligencia en la responsabilidad social empresarial supone el cuidado y remedio de las vulneraciones a derechos humanos. Sin embargo, así como ellos constituyen un límite para la inversión extranjera, en ocasiones la inversión también se ve limitada por los derechos humanos.

Por último, cabe resaltar que formalmente estos principios y reglas no son vinculantes para las empresas multinacionales, mas, sin embargo, se puede ver que hay una amplia coincidencia teleológica y regulatoria con las directrices de la OCDE. Igualmente, en la práctica se ha dado 
que estos principios se hacen vinculantes a partir de su inclusión en cláusulas propias de los contratos de inversión o financiación (ILA, 2016).

\section{Las obligaciones constitucionales de los inversionistas en Colombia}

Finalmente, con relación a la debida diligencia del inversionista extranjero a la hora de invertir en Colombia, es importante destacar que este debe tener como mínimo conocimiento previo y detallado del ordenamiento jurídico constitucional. Esto se deriva, por un lado, de la redacción de algunos de los tratados internacionales en materia de inversión; y, por el otro, de nuestro propio sistema normativo.

En el caso del primer punto, los TBI, como el que se firmó entre Colombia y el Reino Unido o entre Estados Unidos y Costa Rica, prevén dentro de su articulado que las inversiones que se hagan en el marco del tratado serán admitidas siempre que se efectúen de conformidad con la legislación nacional del Estado receptor. Esto quiere decir que, a pesar de los estándares internacionales de protección, los inversionistas deben acatar a cabalidad las normas nacionales relativas a la inversión que se vaya a realizar. En otras palabras, la inversión debe seguir todos los parámetros nacionales y cumplir con todos los requisitos previstos en el Estado receptor, aun cuando se trate de inversiones específicas en sectores como el extractivo o financiero, que suponen requisitos adicionales.

Al respecto vemos que algunos tribunales, como en el caso de Alasdair Ross Anderson contra Costa Rica, los árbitros comprobaron que la inversión sí estuviese cobijada por el tratado y que tuviera lugar a la protección derivada de los estándares allí previstos, toda vez que esta se hubiese hecho "de acuerdo con la ley nacional de Costa Rica" (ICSID, Alasdair Ross Anderson et al. vs. Republic of Costa Rica, 2010). Así las cosas, podemos concluir que algunos tribunales de inversión han entendido que cuando el tratado de inversión incluye en alguna de sus disposiciones el requisito de conformidad con la ley nacional del Estado receptor, este debe ser tenido como una dimensión de la debida diligencia mínima que los inversionistas deben emplear a la hora de efectuar sus inversiones. 
Lo anterior cobra mayor sentido y fuerza en contextos como el del ordenamiento jurídico colombiano. Esto debido a que, de acuerdo con nuestro sistema normativo, los extranjeros residentes en el territorio nacional también están llamados a cumplir la legislación nacional y las disposiciones constitucionales. Para ello es esencial remitirnos a los artículos 95 y 100 de la Constitución Política, de los cuales podemos concluir que los extranjeros que habitan en el territorio tienen la obligación de cumplir la Constitución y las leyes nacionales. Con ello podríamos decir que los inversionistas, desde el derecho nacional, terminan obligados a una debida diligencia en dos niveles: una constitucional y una legal.

En el caso de la diligencia constitucional, su punto de partida es el artículo $4^{\circ}$ de la Constitución, que proclama la supremacía constitucional de esta y, por lo tanto, supone que, en el ejercicio de las actividades que se desarrollen dentro del territorio colombiano, es necesario que se tomen en consideración las disposiciones constitucionales para respetar los bienes e intereses allí protegidos. Esto en pocas palabras quiere decir que la Constitución debe mediar como carta de navegación y manual de buenas prácticas de los inversionistas mientras que perdure su inversión en el país, en especial si tenemos en cuenta la jerarquía infraconstitucional que ostentan los TBI en Colombia (Rivas-Ramírez, 2017, 2020).

El artículo 95 también establece una serie de obligaciones puntuales, dentro de las cuales podemos identificar como deber explícito de toda persona en el territorio nacional el no abusar de los derechos propios, respetar los ajenos y propender por la protección de los recursos naturales y el medio ambiente sano. Esto quiere decir que, conectado con el artículo 58, en el que se instituye la función social y ecológica de la propiedad privada, las actividades desarrolladas en el marco de la inversión deben en todo caso responder a criterios que tiendan a la protección de la Constitución ecológica y el orden social de la nación. Y, de igual manera, es imperativo recordar que en el marco de las obligaciones constitucionales - tanto del Estado como de los particularesexisten deberes que no pueden ser pasados por alto, como ocurre con la consulta previa y la participación ambiental (Robledo Silva \& Rivas -Ramírez, 2020a, 2020b). 
Pero, por otra parte, y en atención al sistema normativo derivado de los artículos $4^{\circ}$ y 230 de la Carta, el inversionista también tiene que obrar mediante una debida diligencia legal. Con esto nos referimos a que tiene que acatar y seguir todas las leyes colombianas relacionadas con la ejecución de su proyecto de inversión (Castillo Meneses, 2021). Esto significa que tendrá una doble carta de navegación, que en todo caso lo dirigirá hacia un mismo camino, el del cumplimiento y respeto de los bienes e intereses preponderantes dentro del ordenamiento jurídico colombiano.

Ahora bien, la cuestión relacionada con el acatamiento y la obligatoriedad del derecho nacional colombiano para los inversionistas cobra mayor fuerza en tanto se dé una lectura transversal con lo que hemos señalado en el primer acápite. Esto debido a que, como es previsible, uno de los primeros factores que deben ser considerados antes de realizar la indicación y priorización del proyecto de inversión es el ordenamiento jurídico al cual quedará sometida.

Con esto nos referimos a que antes de llevar a cabo materialmente la inversión, se esperaría que el inversionista estudiase y se familiarizase con sus condiciones jurídicas, por lo menos, con aquellas consagradas constitucionalmente. Esto para decir, tal y como lo veremos a continuación en el análisis de caso, que hay determinadas medidas $\mathrm{y}$ actuaciones estatales que son previsibles y justificadas a partir del texto constitucional y que, de haberse hecho el estudio de viabilidad jurídica, se habría detectado la incompatibilidad física y jurídica de la realización de la inversión.

Así las cosas, la debida diligencia del inversionista extranjero entendida desde su dimensión externa implica que sus inversiones se planeen, ejecuten y desarrollen en concordancia con el régimen constitucional vigente del Estado receptor de la inversión, y, en todo caso, cumpliendo, previniendo y respetando los derechos humanos de las diferentes comunidades a las que pueda afectar. En tal sentido, desde esta segunda dimensión, la debida diligencia implica una serie de obligaciones respecto de terceros que al final le son exigibles a cualquier otro particular que opere dentro de un estado social de derecho, en condiciones de igualdad. 


\section{E1 incumplimiento a los deberes de debida diligencia en el caso de Cosigo y Tobie Mining}

Para efectos de evaluar el caso referido, procuraremos mantener el mismo esquema metodológico que se ha empleado a lo largo de este artículo. Para ello, vemos cómo estas multinacionales no cumplieron con los mínimos que deberían de acuerdo con el normal porvenir de las inversiones. Posteriormente, describiremos cómo actuaron en desmedro de su debida diligencia al actuar en contra de lo establecido por el ordenamiento jurídico colombiano. Finalmente, ofreceremos algunas consideraciones finales en torno al caso eventual en el que se hubiesen acogido a las directrices de la OCDE y a los Principios Ruggie.

\section{Tobie Mining y Cosigo fallaron en su proceso de planificación, evaluación y locación de la inversión}

Ya señalábamos páginas atrás la importancia que tiene para el éxito de una inversión el proceso previo de reflexión y toma de decisiones con relación a este tipo de proyectos. Los riesgos, tanto financieros como jurídicos y sociales, a los que se enfrenta una iniciativa de este tipo deben ser tenidos en cuenta y deben ser determinantes para la decisión final sobre invertir o no. De lo contrario, la inversión que se haga no estará respondiendo a la lógica económica ni mucho menos a los intereses finales de las empresas multinacionales.

En el caso que motivó la demanda internacional de Cosigo y Tobie Mining contra Colombia, vemos que la decisión de realizar la inversión en el proyecto minero del Taraira Sur en Colombia respondió a un mal proceso decisorio, en el que se tomó una decisión precipitada, previendo un vacío regulatorio en materia minera, sin considerar los fundamentos e intereses constitucionales que podrían entrar en juego. A partir de una sencilla revisión de la regulación legal, está claro que la protección legal y constitucional de los recursos naturales y del territorio comprendido por el proyecto antecede incluso la fundación de una de estas compañías. Cosigo Resources Limited fue fundada 38 años después de que se declararla la constitución del ZRF de la Amazonía por la Ley 2 de 1959 y un año antes de que se reconociera jurídicamente 
el Resguardo Indígena Yaigojé Apaporis, en 1988 (Robledo Silva E Rivas-Ramírez, 2019).

Con ello queremos mostrar que la protección y relevancia medioambiental de la zona sobre la que se diseñó y promovió el proyecto minero en cuestión existía mucho antes de que siquiera el interés de las multinacionales surgiese. Sin embargo, tanto el hecho de la constitución de la zona de reserva forestal (ZRF) como el reconocimiento del resguardo indígena nos resultan útiles para demostrar cómo se falló en el proceso de toma de decisiones de las multinacionales.

Es así como en el año 2007 cuando la empresa (en ese entonces Tobie Mining) manifestó su interés por iniciar un proyecto de exploración y explotación aurífera en los tres yacimientos de la zona del Taraira al norte del Amazonas y al oriente del Vaupés, tanto la ZRF como el resguardo ya existían. En consecuencia, de haber estudiado no solo la viabilidad física del proyecto, sino también la esfera normativa relevante, habría sido posible concluir que el riesgo real para la inversión era sustancialmente alto y, por lo tanto, no sería rentable proceder a ella.

Sumado a lo anterior y aun cuando se hubiese cometido ese primer error en el desarrollo del proyecto, Ingeominas le notificó en su momento de manera clara a través de una comunicación del 14 de abril de 2009 (meses antes de la suscripción y registro del Contrato de Concesión IGH-15001X) acerca de la sobreposición de los yacimientos con la ZRF y el resguardo indígena. Esto quiere decir que en ese momento la multinacional habría podido hacer una reevaluación de sus posibilidades y detener la proyección de la inversión, toda vez que de entrada se le estaba notificando de la imposibilidad de ejecutar la exploración y explotación si no se cumplía con los requisitos previstos para ello en este tipo de casos, a saber, comprobar que podrían coexistir ambas actividades, la totalidad de los permisos o licencias ambientales y la realización de la consulta previa.

Al respecto es necesario destacar entonces que, dentro del ejercicio de trazabilidad de la inversión y la factibilidad del proyecto minero, sumado a las advertencias realizadas por Ingeominas en su debido momento, el estudio del ordenamiento constitucional habría sido vital para poder prever que el proyecto no podría haberse efectuado bajo ninguna circunstancia. 


\section{Una debida diligencia que brilla por su ausencia en las actuaciones dentro del ordenamiento jurídico nacional}

Ahora bien, más allá de lo que el inversionista debió haber hecho antes de ejecutar parte de su inversión, también quedan las vulneraciones a la debida diligencia que estaba llamado a cumplir durante su ejecución y su permanencia en Colombia.

Para empezar, si bien es cierto que la compañía inició de manera preliminar un tipo de consulta previa con algunas de las comunidades indígenas y ancestrales de la zona para contar con su aval para el proyecto minero, este procedimiento se vio viciado por dos circunstancias diferentes. En primer lugar, el proceso de consulta previa fue realizado de manera parcial, lo que quiere decir que no abarcó la totalidad de comunidades que se verían afectadas por parte del proyecto, toda vez que excluyó a más de la mitad de ellas (Corte Constitucional, Sentencia T-384A/2014). Pero, sumado a ello, la segunda causa del vicio de la consulta previa efectuada por la compañía fue lo que, dentro de casos como Silvermining contra Bolivia, se ha conocido como fabricación de consentimiento (PCA, South American Silver Limited vs. Bolivia, 2013). Esto dado que en el caso en concreto la multinacional consiguió moldear la voluntad de las comunidades participantes a través de promesas como el reconocimiento del $20 \%$ de las ganancias de la explotación (Corte Constitucional).

No siendo poco esto, la multinacional así mismo intercedió para que las comunidades indígenas agrupadas en Acitava interpusieran una acción de tutela en contra de la constitución del Parque Yaigojé Apaporis. No obstante, en el transcurso del proceso judicial salió a la luz, del testimonio mismo de los accionantes, que la compañía les había ofrecido prebendas y contraprestaciones a cambio de la participación en la acción (Corte Constitucional).

En conclusión, con relación a las diferentes manifestaciones de la consulta previa, es claro que Cosigo y Tobie Mining actuaron en contra del ordenamiento jurídico, manipulando herramientas propias para la protección y defensa de los derechos humanos, hasta tal punto que la misma Corte Constitucional ordenó compulsar copias al Ministerio del Interior para que adelantase las investigaciones correspondientes. 
Adicionalmente, cabe destacar que las actividades propuestas para desarrollarse por parte del proyecto minero suponían también un atentado directo contra una zona doblemente ( $y$, posteriormente, triplemente) protegida, que además suponía una violación de los mandatos constitucionales respecto a la protección del medio ambiente y la función ecológica de su propiedad.

\section{Consideraciones finales en torno al actuar de Tobie Mining y Cosigo}

Finalmente, cabe destacar que los comportamientos realizados ex ante y posteriores a la inversión constituyen una clara falta a su deber de debida diligencia, consigo mismos, pero también con el Estado colombiano. En este caso en particular, vemos que la vulneración se concretó a través de una clara materialización de un riesgo propio de la inversión que fue mal calculado, pero, a la vez, en la materialización de un riesgo para los derechos humanos y el medio ambiente.

Es por esta razón que en caso tal en el que Tobie Mining o Cosigo estuviesen abiertos a las directrices de la OCDE o a los Principios Ruggie sería aún más fácil llegar a esta conclusión, en especial si se tiene en cuenta que en lo que respecta al segundo riesgo que se ha concretado la empresa no ha hecho nada hasta el momento para efectos de remediar o mitigar las consecuencias negativas y los efectos colaterales que sus decisiones han causado dentro del escenario colombiano.

\section{A modo de conclusión}

El derecho internacional de las inversiones es una de las ramas del derecho internacional que, dado su origen, su objeto y su naturaleza, se caracteriza por ser altamente técnico, asimétrico y críptico. Incluso, autores como Prieto Ríos lo describen como un sistema de violencia sistémica $(2018,2020)$ que afecta los intereses y derechos nacionales. En concreto, debido a la estructura y funcionamiento neocolonial de los TBI y el diseño del arbitraje de inversión, es frecuente encontrar que 
los inversionistas extranjeros suelen contar con amplias herramientas que les permiten llevar a los Estados a los estrados internacionales, en donde, además, suelen contar con el apoyo -implícito- de los árbitros. En otras palabras, el derecho internacional de las inversiones está pensado y construido para que las inversiones estén plenamente protegidas, $\mathrm{y}$, por lo tanto, al Estado se le pueda exigir el cumplimiento de los más altos niveles de protección y seguridad.

A partir de este contexto y de la realidad en la que la tendencia a la condena de los Estados en vía de desarrollo suele ser bastante mayor, es necesario pensar en la búsqueda de herramientas -tanto prácticas como teóricas- para la defensa de los Estados en los estrados arbitrales. De allí que hayamos empezado por examinar un concepto que, pese a no estar del todo claro en el marco del derecho internacional de las inversiones, resulta interesante y oportuno para la defensa estatal. Así, a partir de un análisis teórico, doctrinal y 'jurisprudencial', argumentamos que la debida diligencia es una obligación con la que deben cumplir los inversionistas extranjeros en varios niveles.

Más concretamente, hemos propuesto la definición de la debida diligencia como un concepto híbrido multinivel en la medida en la que involucra deberes de los inversionistas respecto de ellos mismos, respecto de los Estados y respecto de los individuos en general. Frente a las obligaciones que deben cumplir con ellos mismos, analizamos teóricamente aquellas que deben cumplir en virtud de su propia actividad económica bajo la lógica de la diligentia quam in suis, el buen pater familias y la lex artis, y de los compromisos voluntarios que suelen asumir. En cuanto a las obligaciones frente a los Estados y los individuos, lo sustentamos en clave de la debida diligencia constitucional, legal y social empresarial.

Finalmente, para efectos de poner a prueba la definición propuesta, analizamos el caso que motivó la demanda de las multinacionales Cosigo y Tobie Mining contra Colombia para determinar si en realidad estas habrían cumplido o no con los estándares de debida diligencia que hemos identificado. Análisis a partir del cual queda evidenciado que, al menos en el contexto colombiano, esta definición podría resultar útil y aportar herramientas para la defensa del Estado ante un tribunal de inversión. 


\section{Referencias}

Alabama Claims Arbitration (United States/Great Britain) (1872) 29 RIAA 125. AWG Group Ltd. versus The Argentine Republic. ARB/03/19, Decision on liability, 30 July 2012.

Cantú Rivera, H. (2015). La OCDE y los derechos humanos: el caso de las directrices para empresas multinacionales y los puntos de contacto. Anuario Mexicano de Derecho Internacional, XV, 611-658.

Castillo Meneses, Y. (2021). El impacto de las medidas ambientales en el estándar de expropiación indirecta: el caso Eco Oro c. Colombia. Revista de Derecho, (54), 247-289. https://doi.org/10.14482/dere.54.346.4

Cheteil, V. (2014). The legal personality of multinational corporations, State responsibility and due diligence: the way forward. In D. Alland, V. Cheteil, O. de Frouville \& J. E. Viñuales, Unity and diversity of international law. Essays in honour of prof. Pierre-Marie Dupuy (pp. 105-130). Leiden: Martinus Nijhoff. Colombia, Corte Lotus Constitucional. Sentencia T-384A de 2014. CPII. SS Lotus (France vs. Turkey), 1927, PCIJ (Ser. A) N 10.

Denisia, V. (2010). Foreign direct investment theories: an overview of the main FDI theories. Economic Journal of Interdisciplinary Studies, 2(2), 104-110.

Fellmeth, A., \& Horowitz, M. (2011). Guide to Latin in international law. Oxford: Oxford University Press.

Henisz, W., \& Zelner, B. A. (2010). The hidden risks in emerging markets. Harvard Business Review. Available from https://hbr.org/2010/04/thehidden-risks-in-emerging-markets

Hernández, G. I. (2013). The interaction between investment law and the law of armed conflict in the interpretation of full protection and security clause. In F. Baetens, Investment law withing international law (pp. 21-50). Cambridge: Cambridge University Press.

ICSID. (2000). Salini Costruttori S.p.A. and Italstrade S.p.A. versus Kingdom of Morocco. ICSID Case ARB/00/4.

ICSID. (2003). Técnicas Medioambientales Tecmed S.A. versus The United Mexican States. ICSID Case ARB (AF)/00/2, Award, 29 May 2003.

ICSID. (2007). Parkerings-Compagniet As versus Republic of Lithuania. Award, 11 Sep 2007. Parkerings-Compagniet AS versus Republic of Lithuania. ICSID Case ARB/05/8.

ICSID. (2008a). Biwater Gauff (Tanzania) Ltd. versus United Republic of Tanzania. Award, 24 Jul 2008. Biwater Gauff (Tanzania) Ltd. versus United Republic of Tanzania. ICSID Case ARB/05/22. 
ICSID. (2008b). Jan de Nul N.V. E Dreding International N.V. c. Arab Republic of Egypt. ICSID Case ARB/04/13, Award, 6 November 2008.

ICSID. (2010). Alasdair Ross Anderson et al. versus Republic of Costa Rica. Award, 19 May 2010. Alasdair Ross Anderson et al. versus Republic of Costa Rica. ICSID Case ARB(AF)/07/3.

ICSID. (2021). Naturgy Energy Group S.A. E Naturgy Electricidad Colombia S.L. versus República de Colombia. ICSID Case UNCT/18/1.

ILC. (2001a). Draft articles on responsibility of States for internationally wrongful acts, with commentaries 2001. Adopted by the International Law Commission at its fifty-third session, in 2001, and submitted to the General Assembly as a part of the Commission's report covering the work of that session (A/56/10).

ILC. (2001b). Draft articles on prevention of transboundary harm from hazardous activities, with commentaries. Adopted by the International Law Commission at its fifty-third session, in 2001, and submitted to the General Assembly as a part of the Commission's report covering the work of that session (A/56/10).

ILA. (2014). ILA Study Group on Due Diligence in International Law. First report, March 2014 finalized by Tim Stephens (rapporteur) and Duncan French (chair). ILA. (2016). ILA Study Group on Due Diligence in International Law. Second report, July 2016 finalized by Tim Stephens (rapporteur) and Duncan French (chair). IMF, E World Bank. (2003). Foreign direct investment in emerging market countries, report of the Working Group of the Capital Markets Consultative Group.

Kaganova, O. (2011). Guidebook on capital investment planning for local governments. Urban development series, knowledge papers $\mathrm{N}^{\circ} 13$. World Bank: Washington, DC.

Koskenniemi, M. (2006). From apology to utopia: the structure of international legal argument. Cambridge: Cambridge University Press.

Kulesza, J. (2016). Due diligence in international law. Leiden-Boston: Brill Nijhoff. McDearman, B., E Donahue, R. (2016). FDI planning guide: a blueprint for metro teams pursuing global economic engagement. Global Cities Initiative. Brookings \& JP Morgan Chase. Available from https://www.brookings. edu/wp-content/uploads/2016/07/BMPP_FDIGuide_Phase3May5-1.pdf

McGowan Jr., C. B., \& Moeller, S. E. (2009). A model for making foreign direct investment decisions using real variables for political and economic risk analysis. Managing Global Transitions, 7(1), 27-44.

Neme Villarreal, M. L. (2006). El principio de buena fe en materia contractual en el sistema jurídico colombiano. Revista de Derecho Privado, (11), 79-126. 
OACNUDH. (2011). Guiding principles on business and human rights: implementing the United Nations 'protect, respect and remedy' framework. Available from http://www.ohchr.org/Documents/Publications/GuidingPrinciplesBusinessHR_EN.pdf

OECD. (2011). OECD guidelines for multinational enterprises. OECD Publishing.

OECD. (2016). Due diligence guidance for responsible supply chains of minerals from conflict-affected and high-risk areas ( $3^{\text {rd }}$ ed.). Paris: OECD Publishing.

Ostau de la Font de León, F. R., E Niño Chavarro, L. A. (2015). Criterios de aplicabilidad en el punto nacional de contacto colombiano de las líneas directrices de la OCDE en materia laboral (convenios 87 y 98 de la OIT) para las empresas multinacionales. Revista Republicana, (18), 39-69.

Pissilo-Mazzeschi, R. (1992). The due diligence and the nature of the international responsibility of States. German Yearbook of International Law, (35), 9-51.

Prieto-Ríos, E. (2018). Encrypted international investment law. In R. Sanin-Restrepo (Ed.), Decrypting power (pp. 49 y ss.). London: Rowman E Littlefield.

Prieto-Ríos, E., E Rivas-Ramírez, D. (2020). Neocolonialism and the tension between international investment law and Indigenous peoples: the Latin American experience. In J. Borrows \& R. Schwartz (Eds.), Indigenous peoples and international trade. Building Equitable and inclusive international trade and investment agreements (pp. 85-108). Cambridge: Cambridge University Press. https://doi.org/10.1017/9781108675321.006

Rivas-Ramírez, D. (2017). El derecho internacional de las inversiones, otro de los desaires de la jurisprudencia constitucional colombiana. En J. I. Acosta López, P. A. Acosta Alvarado \& D. Rivas-Ramírez (Eds.), De anacronismos $y$ vaticinios: diagnóstico sobre las relaciones entre el derecho internacional y el derecho interno en Latinoamérica (pp. 627-660). Bogotá: Universidad Externado de Colombia.

Rivas-Ramírez, D. (2018). El vicio surrealista del monismo y el dualismo ante la metamorfosis del derecho internacional público. En F. Padrón Pardo \& M. Correa Henao (Eds.), ¿El Estado constitucional en jaque? El Estado constitucional y el derecho internacional (pp. 45-78). Bogotá: Universidad Externado de Colombia.

Rivas-Ramírez, D. (2020). La recepción del derecho internacional de las inversiones en la Corte Constitucional: breve análisis a partir de su jurisprudencia. En E. H. Fuentes Contreras \& D. Rivas-Ramírez (Eds.), Método(s) y derecho(s): construcciones alternativas de lineas jurisprudenciales para derechos y garantías (pp. 29-63). Bogotá: Tirant lo Blanch-Editorial UTadeo. 
Robledo Silva, P., E Rivas-Ramírez, D. (2019). Cuando la leyenda de El Dorado se hace realidad: análisis sobre las tensiones entre los intereses económicos y los derechos de los pueblos indígenas. En J. Tole Martínez (Ed.), Derechos humanos y la actividad empresarial en Colombia: implicaciones para el estado social de derecho (pp. 48-75). Bogotá: Universidad Externado de Colombia.

Robledo Silva, P., E Rivas-Ramírez, D. (2020a). Pueblos indígenas y derecho internacional de las inversiones: alternativas para una mayor participación. En M. P. García Pachón (Ed.), Información, participación y justicia ambiental. Herramientas para alcanzar el desarrollo sostenible y la democracia ambiental (pp. 274-314). Bogotá: Universidad Externado de Colombia.

Robledo Silva, P., \& Rivas-Ramírez, D. (2020b). Una breve lectura en clave indígena de la jurisprudencia constitucional colombiana del 2019 sobre tratados de inversión. Anuario Iberoamericano de Justicia Constitucional, 24(2), 559-572. https://doi.org/10.18042/cepc/aijc.24.19

Ruggie, J. G. (s. f.). The social construction of the UN guiding principles on business and human rights. Corporate Responsibility Initiative Working Paper $\mathrm{N}^{\mathrm{o}}$ 67. Cambridge, MA: John F. Kennedy School of Government, Harvard University.

Sabogal, L. F. (2012). El margen discrecional de los administradores en Colombia: ¿es aplicable la 'regla del buen juicio empresarial' [business judgment rule (BJR)] en el ámbito de su deber de diligencia? Revista e-mercatoria, 11(1), 102-163.

SCC. Iurii Bogdanov, Agurdino-Invest Ltd. and Agurdino-Chimia JSC versus Republic of Moldova.

Schreuer, C. (2000). ICSID Convention: a commentary. Cambridge: Cambridge University Press.

Stephens, T. (2009). International courts and environmental protection. Cambridge: Cambridge University Press.

Suez, Sociedad General de Aguas de Barcelona S.A. and Vivendi Universal S.A. versus The Argentine Republic. ARB/03/19, Decision on liability, 30 July 2010.

Uncitral. (2001). Ronald S. Lauder versus The Czech Republic. Uncitral, Final award, 3 September 2001.

Uncitral. (2013). South American Silver Limited versus Bolivia. Uncitral, PCA Case 2013-15. 